\title{
A Fiber-Integrated CRDS Sensor for In-Situ Measurement of Dissolved Carbon Dioxide in Seawater
}

\author{
Mai Hu ${ }^{1,2}$, Bing Chen ${ }^{1}$, Lu Yao ${ }^{1}$, Chenguang Yang ${ }^{3}$, Xiang Chen ${ }^{1}$ and Ruifeng Kan ${ }^{1, *}$ \\ 1 Anhui Institute of Optics and Fine Mechanics, Hefei Institute of Physical Science, Chinese Academy of \\ Sciences, Hefei 230031, China; humai@aiofm.ac.cn (M.H.); bchen@aiofm.ac.cn (B.C.); \\ lyao@aiofm.ac.cn (L.Y.); xchen@aiofm.ac.cn (X.C.) \\ 2 University of Science and Technology of China, Hefei 230026, China \\ 3 Institute of Deep-Sea Science and Engineering, Chinese Academy of Sciences, Sanya 572022, China; \\ yangcg@idsse.ac.cn \\ * Correspondence: kanruifeng@aiofm.ac.cn; Tel.: +86-0551-65593695
}

Citation: Hu, M.; Chen, B.; Yao, L.; Yang, C.; Chen, X.; Kan, R. A FiberIntegrated CRDS Sensor for In-Situ Measurement of Dissolved Carbon Dioxide in Seawater. Sensors 2021, 21, 6436. https://doi.org/10.3390/ s21196436

Academic Editor: Jin Li

Received: 21 August 2021

Accepted: 24 September 2021

Published: 27 September 2021

Publisher's Note: MDPI stays neutral with regard to jurisdictional claims in published maps and institutional affiliations.

Copyright: (c) 2021 by the authors. Licensee MDPI, Basel, Switzerland. This article is an open access article distributed under the terms and conditions of the Creative Commons Attribution (CC BY) license (https:// creativecommons.org/licenses/by/ $4.0 /)$.

\begin{abstract}
Research on carbon dioxide $\left(\mathrm{CO}_{2}\right)$ geological and biogeochemical cycles in the ocean is important to support the geoscience study. Continuous in-situ measurement of dissolved $\mathrm{CO}_{2}$ is critically needed. However, the time and spatial resolution are being restricted due to the challenges of very high submarine pressure and quite low efficiency in water-gas separation, which, therefore, are emerging the main barriers to deep sea investigation. We develop a fiber-integrated sensor based on cavity ring-down spectroscopy for in-situ $\mathrm{CO}_{2}$ measurement. Furthermore, a fast concentration retrieval model using exponential fit is proposed at non-equilibrium condition. The in-situ dissolved $\mathrm{CO}_{2}$ measurement achieves 10 times faster than conventional methods, where an equilibrium condition is needed. As a proof of principle, near-coast in-situ $\mathrm{CO}_{2}$ measurement was implemented in Sanya City, Haina, China, obtaining an effective dissolved $\mathrm{CO}_{2}$ concentration of $\sim 950 \mathrm{ppm}$. The experimental results prove the feasibly for fast dissolved gas measurement, which would benefit the ocean investigation with more detailed scientific data.
\end{abstract}

Keywords: seawater dissolved gas; carbon dioxide; optical cavity ring-down spectroscopy; in-situ measurement

\section{Introduction}

Marine carbon cycling is the result of a series of physical, geological and biological processes on a spatiotemporal scale [1,2]. The ocean absorbs one-third of the anthropogenic carbon emission, about 2 billion tons per year. As such, the ocean becomes one important place for carbon sequestration [3]. Furthermore, $\mathrm{CO}_{2}$ is the main greenhouse gas, the main dissolved gas of seawater and the main fluid component of the deep-sea extreme window of cold spring and hydrothermal solution. Precise measurement on its spatiotemporal distribution is significant to investigate the biogeochemical material cycle and global climate change [4,5]. However, common methods based on sampling-laboratory analysis are not enough to support modern marine science. In-situ $\mathrm{CO}_{2}$ sensors with high sensitivity, high fidelity, large dynamic range and fast response are highly needed in many cutting-edge research topics, such as the sea-air exchange flux of $\mathrm{CO}_{2}[6], \mathrm{CO}_{2}$ concentration of deep-sea cold spring and hydrothermal fluid components [7-9], and isotope measurement [7,8,10,11].

Currently, optical technology, semiconductor gas sensing and mass spectrometry $[8,9,11-13]$ are common methods in in-situ measurement of dissolved gas in seawater. Among them, laser-based in-situ optical spectrometer is suitable for greenhouse gas sensing in seawater due to its unique selectivity and sensitivity $[12,14,15]$. Using infrared spectroscopy technology, the German Hydro C company demonstrated dissolved $\mathrm{CH}_{4}$ measurement in seawater [16]. Using the off-axis integrated cavity output spectroscopy (OA-ICOS), the LGR Company in the United States measured the dissolved $\mathrm{CH}_{4} / \mathrm{CO}_{2}$ and 
its isotope $\delta^{13} \mathrm{CH}_{4}$ in seawater [11]. Using mid-infrared absorption spectroscopy technology, Zheng Chuantao et al. achieved the measurement of dissolved $\mathrm{CO}_{2}$ and its isotope $\delta^{13} \mathrm{CO}_{2}$ [12]. In addition, cavity ring-down spectroscopy (CRDS), proposed by $\mathrm{O}$, Keefe and Deacon in 1988 [17], has ultra-high detection sensitivity, light intensity jitter immunity and free instrument calibration, making CRDS one of the best candidates for gas detection. The past years have witnessed its remarkable progresses in precision spectroscopy [18-20] and important applications in atmospheric trace gas measurement [21-23]. However, the application of this technology in the marine field for in-situ measurement remains unresolved due to the challenges of high stability resonant cavity, high precision/low power circuit and time-consuming dissolved gas concentration retrieval.

In this paper, we report the development of an in-situ CRDS based dissolved $\mathrm{CO}_{2}$ sensor. A fast exponential regression model is proposed to retrieve the concentration of dissolved gas in seawater. In the implementation, we design high-pressure assembling and use polydimethylsiloxane (PDMS) membrane for water/gas separation and enrichment [24,25]. A long-time in-situ observation near the coast is carried out to prove the feasibility of in-situ separation, enrichment and measurement of dissolved $\mathrm{CO}_{2}$ in seawater.

\section{Principle of CRDS-Based Seawater Dissolved Gas Measurement}

\subsection{Water/Gas Separation and Enrichment, and Dissolved Gas Retrieval}

A PDMS membrane is one common tool, as the gas-liquid interface with a thickness of 1 , to separate and enrich seawater dissolved gases [26,27]. The concentration difference between both sides enables the dissolved gas pass through the membrane and blocks liquid water molecule $\left(\mathrm{H}_{2} \mathrm{O}\right)_{n}$. Thus, small gas molecules, such as $\mathrm{CH}_{4}, \mathrm{CO}_{2}$ and $\mathrm{O}_{2}$ can be separated from seawater. The water/gas separation of PDMS membrane is typically described by the "dissolution-diffusion" model $[24,26]$. When concentration difference between both sides exists, gas molecules diffuse into the membrane and realize gas exchange.

In the case of a stable situation, the dissolved gas concentration remains stable along the direction of film thickness. The diffusion flux on the side of the gas chamber can be expressed by Fick's first law [24,26,27]:

$$
F_{G}=\frac{D_{G} S_{G} A\left(P_{G 1}-P_{G 2}\right)}{l},
$$

where $F_{G}\left(\mathrm{~cm}^{3} \cdot \mathrm{cm}^{2}\left(\mathrm{~cm}^{2} \text { polymer }\right)^{-1} \cdot \mathrm{s}^{-1}\right)$ is the diffusion flux of gas component $G$ per unit time, $D_{G}\left(\mathrm{~cm}^{2} \cdot \mathrm{s}^{-1}\right)$ is the diffusion coefficient of gas component $G$ in the membrane, $S_{G}\left(\mathrm{~cm}^{3} \cdot\left(\mathrm{cm}^{2} \text { polymer }\right)^{-1} \cdot \mathrm{Pa}^{-1}\right)$ is the solubility coefficient of gas component $G$ in the membrane, $P_{G 1}(\mathrm{~Pa})$ is the partial pressure of seawater dissolved gas $G, P_{G 2}(\mathrm{~Pa})$ is the partial pressure of gas component $G$ in the gas chamber, $A\left(\mathrm{~cm}^{2}\right)$ is the film area, $l(\mathrm{~cm})$ is the film thickness. While gas diffusion flux can be expressed by Fick's second law in the case of unstable situation $[25,26]$ :

$$
F_{G, t}=F_{G, s s}\left(1+2 \sum_{n=1}^{\infty}(-1)^{n} \exp \left\{\frac{-n^{2} \pi^{2} D_{G} t}{l^{2}}\right\}\right),
$$

where, $F_{G, t}$ is the gas flux at time $t, F_{G, s s}$ is the gas flux in the stable situation.

The diffusion coefficient of $\mathrm{CO}_{2}$ in PDMS membrane is about $1.5 \times 10^{-5} \mathrm{~cm}^{2} / \mathrm{s}$, $l \ll 1 \mathrm{~cm}, t=1 \mathrm{~s}$, then $\exp \left\{\frac{-n^{2} \pi^{2} D_{G} t}{l^{2}}\right\}$ is almost zero and $F_{G, t} \approx F_{G, s s}$. Thus, the diffusion flux in this case can also be described by Fick's first law. Therefore, the concentration change of the gas component $G$ is as follows:

$$
P_{G 2} * V=\int \frac{D_{G} S_{G} A\left(P_{G 1}-P_{G 2}\right)}{l} d_{t}
$$


where $V$ is the volume of the gas chamber. From Equation (3), we can obtain:

$$
\frac{d_{P_{G 2}}}{d_{t}} * V=\frac{D_{G} S_{G} A\left(P_{G 1}-P_{G 2}\right)}{l},
$$

With the boundary condition, $t \rightarrow \infty, P_{G 2}=P_{G 1}$, it will be extrapolated that:

$$
P_{G 2}=K * \exp \left(-\frac{D_{G} S_{G} A}{l V} t\right)+P_{G 1}
$$

where $\mathrm{K}$ is related to the initial pressure. For non-condensable gases, such as $\mathrm{CO}_{2}$ and $\mathrm{CH}_{4}$, the value of $-\frac{D_{G} S_{G} A}{l V}$ is independent from partial pressure.

After measuring the value of $P_{G 2}$ over time in an unbalanced situation, the exponential regression is used to retrieve $P_{G 1}$. $P_{G 1}$ equals to $P_{G 2}$ in balanced situation.

\subsection{Optical Measurement Using CRDS}

When laser with an intensity of $I_{\text {in }}$ passes through uniform gas substance, the laser decays to $I_{\text {out }}$ due to gas absorption, which can be described by the Beer-Lamber law $[10,17]$ :

$$
I_{\text {out }}=I_{\text {in }} * \exp (-\alpha * L),
$$

where, $\alpha\left(\mathrm{cm}^{-1}\right)$ is the spectral absorption coefficient, $L(\mathrm{~cm})$ is the interaction distance.

In the configuration of CRDS, a couple of high reflectivity mirrors, usually higher than $99.99 \%$, enable a significant interaction length extension inside a limited physical space [28], and become capable of detecting minor absorption of trace gas concentration. Its working principle is shown in Figure 1. When laser beam resonates with one resonant cavity mode, the laser power inside the cavity will be rapidly built up. With a trigger that the inside laser power reaches a certain threshold, the incident laser is quickly cut off to generate a free intracavity ring down. The leaked laser intensity $I_{v}(t)$ after each ring down is successively recorded at the exit to obtain optical intensity that decays with time as follows,

$$
I_{\nu}(\mathrm{t})=I_{0 v} * \exp \left(-\frac{t c}{L_{\text {mirrors }}}\left(1-R+\alpha_{v} L_{\text {mirrors }}\right)\right),
$$

where, $c$ is the speed of light, $t(\mu \mathrm{s})$ is the time, $L_{\text {mirrors }}(\mathrm{cm})$ is the physical distance between the two mirrors, $R$ is the reflectivity of the optical cavity mirror, $\alpha_{v}\left(\mathrm{~cm}^{-1}\right)$ is the spectral absorption coefficient of the specific wavelength; $I_{0 v}$ is the initial laser intensity when the laser is cut off.
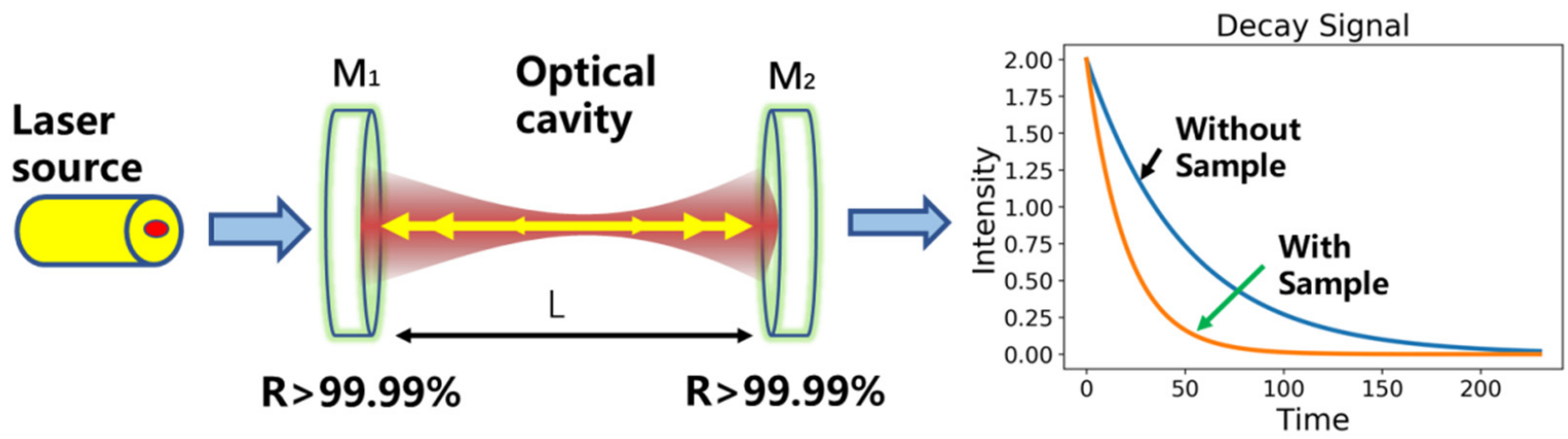

Figure 1. Schematic of the cavity ringdown technique. $\mathrm{M}_{1}$ and $\mathrm{M}_{2}$ : cavity mirrors with high reflectivity (>99.99\%). 
The time for the initial laser intensity reduces to $1 / \mathrm{e}$ in the measurement is defined as the ring-down time [17]. According to Equation (7), in the case of no gas absorption, the empty cavity ring-down time $\tau_{0}$ is:

$$
\tau_{0}=\frac{L_{\text {mirrors }}}{C(1-R)}
$$

In the presence of gas absorption, the ring-down time $\tau_{v}$ is:

$$
\tau_{v}=\frac{L_{\text {mirrors }}}{C\left(1-R+\alpha_{v} L_{\text {mirrors }}\right)},
$$

Combining (8) and (9), we obtain the intracavity spectral absorption coefficient as:

$$
\alpha_{v}=\frac{1}{C \tau_{v}}-\frac{1}{C \tau_{0}}
$$

In the absorption spectrum [29], the absorption coefficient can be expressed as:

$$
\alpha_{v}=S(T) * P_{\text {total }} * X * \psi(v)
$$

where $S(T)\left(\mathrm{cm}^{-2} \cdot \mathrm{atm}^{-1}\right)$ is the intensity of the absorption line, $P_{\text {total }}(\mathrm{atm})$ is the total pressure of the gas, $X$ is the molecular concentration, $\psi(v)(\mathrm{cm})$ is the absorption line shape function.

Since integral of $\psi(v)$ over $v$ is equals 1, i.e., $\int_{-\infty}^{+\infty} \psi(v) d_{v}=1, S(T)$ relates to the temperature for a specific absorption line, and $P_{\text {total }}$ can be measured using a commercial pressure sensor. Therefore, after fitting the absorption coefficient curve to obtain the integrated area $A$, the partial pressure of the gas can be calculated by:

$$
P=X P_{\text {total }}=\frac{A}{S(T)},
$$

Thus, the partial pressure of dissolved gas $\left(P_{G 1}\right)$ can be retrieved by measuring the partial pressure of gas $\left(P_{G 2}\right)$ in the cavity and fitting formula (5).

\section{In-Situ Dissolved $\mathrm{CO}_{2}$ Sensor Configuration}

Figure 2 depicts the schematic diagram of the optical dissolved- $\mathrm{CO}_{2}$ sensor, which comprises three parts, one pressured chamber, one water/gas separation and enrichment unit and one gas measurement unit. The first part, i.e., the pressure chamber, is a dry titanium alloy chamber with an inner diameter of $128 \mathrm{~mm}$, a length of $750 \mathrm{~mm}$ and a wall thickness of $10 \mathrm{~mm}$. It can withstand a pressure as high as $57 \mathrm{MPa}$, which is suitable for experiments at about $4500 \mathrm{~m}$ under water. The second part, i.e., the water gas separation and enrichment unit consists of a water pump (SEA-BIRD SBE-5T), a PDMS membrane module (membrane thickness $50 \mu \mathrm{m}$, diameter $5 \mathrm{~cm}$, gas separation efficiency $0.034 \mathrm{~mL} / \mathrm{min}$ at $296 \mathrm{~K}$ and 1 atm pressure difference), a drying box, an air pump (KNF NMP05), a filter (Swagelok, SS-2F-05), two needle valves (Swagelok, SS-ORS2) and the gas chamber (optical resonant cavity). With the water pump, the seawater continuously flows through the surface of PDMS membrane at a flow rate of $0.8 \mathrm{~L} / \mathrm{min}$, forming a stable dissolved gas concentration field on the surface of the membrane. The dissolved gas permeates into the PDMS membrane. On the other side of the membrane, the permeated gas is desiccated by the drying box, then enters the gas chamber through the needle valve 1 and the filter, and finally returns to the PDMS membrane module through the filter, the needle valve 2 and the gas pump. Thus, water/gas separation and enrichment can be completed. The needle valve permits a flow rate of approximately $50 \mathrm{~mL} / \mathrm{min}$.

The third part, i.e., the gas detection unit, includes a control circuit (DSP, TMS320C6748, Texas Instruments, Dallas, TX, USA), a DFB laser (NLK1L5GAAA, NEL, Yokohama, Japan), a semiconductor optical amplifier (SOA, BOA1080P, Throlabs, USA), an isolator (PIISO- 
1600-D-L-05-FA, Qinghe Photonics, Shenzhen, China), an optical resonator and a photoelectric detector (GPD, GAP1000FC, GPD Optoelectronics, Salem, MA, USA). Sawtooth signal and step signal generated by the control circuit are combined to drive the laser to achieve laser beam resonance enhancement inside the optical resonator. When the enhanced intracavity laser power, monitored by the detector, exceeds a certain threshold, the incident laser is rapidly cut off using the TTL driven SOA to generate ring-down signal. With the ring down signal recorded, a fast single exponential fitting is performed to calculate the ring down time. After 20 recordings of ring-down time for a single longitudinal mode, the step voltage is reset to match the laser to next longitudinal mode until the whole absorption line of $\mathrm{CO}_{2}$ is covered. With the averaged absorption spectra, the $\mathrm{CO}_{2}$ absorbance and concentration are calculated by spectral fitting algorithm. Finally, the concentration of the seawater side gas is retrieved according to the exponential fitting in the unbalanced situation.

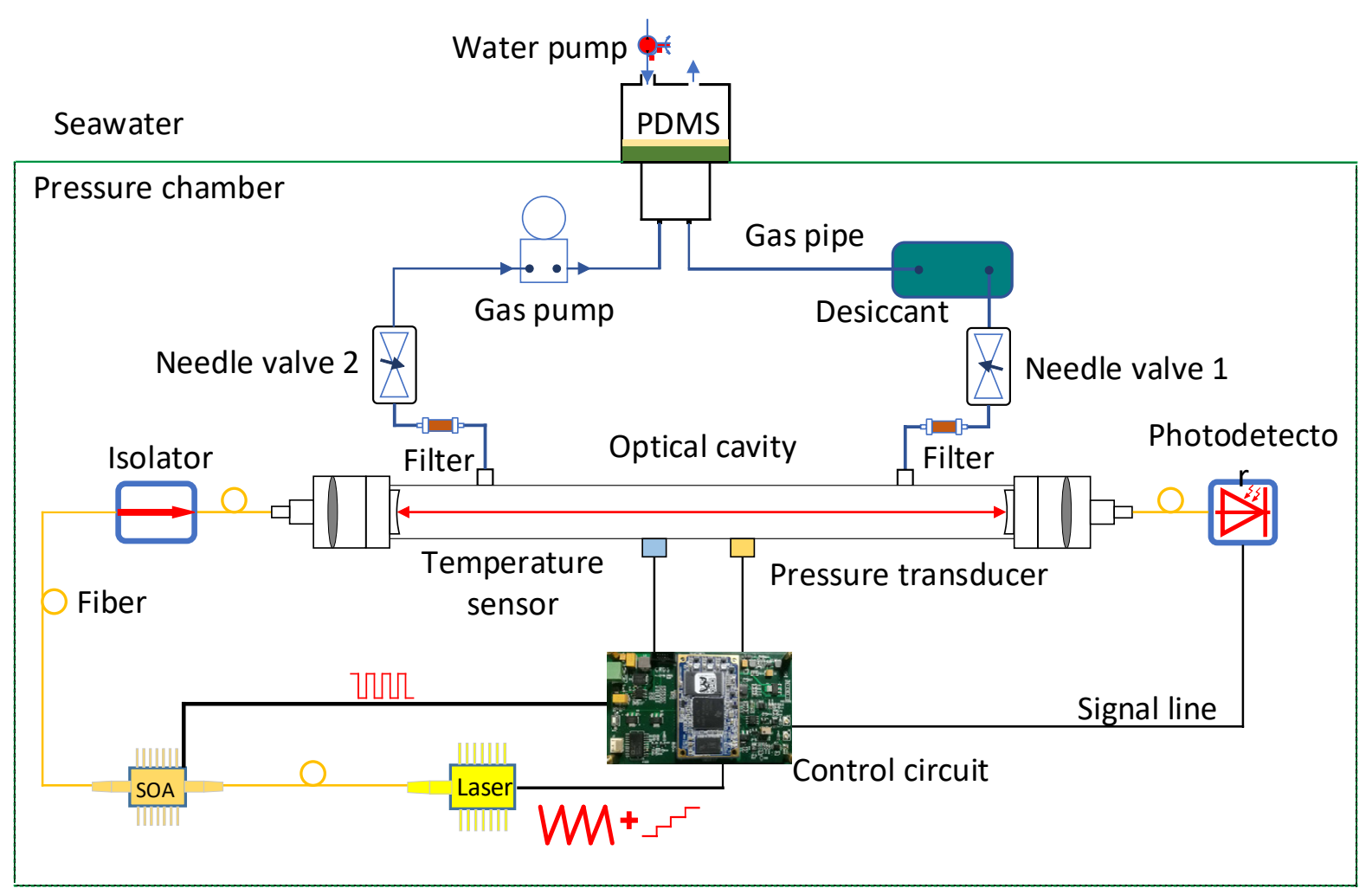

Figure 2. Framework of in-situ underwater instrument for dissolved gas measurement.

\subsection{Absorption Line Selection}

Appropriate absorption line with high absorption intensity and less background interference can benefit the dissolved $\mathrm{CO}_{2}$ measurement with high signal-to-noise ratio. Considering the application condition in seawater dissolved gas measurement, absorption spectra of $\mathrm{CO}_{2},{ }^{13} \mathrm{CO}_{2}, \mathrm{H}_{2} \mathrm{O}$ and $\mathrm{CH}_{4}$ within $1599.4-1599.7 \mathrm{~nm}$ is simulated based on the HITRAN database [30] (temperature: $296 \mathrm{~K}$, gas pressure: $1.01 \times 10^{5} \mathrm{~Pa}, \mathrm{CO}_{2}=400 \mathrm{ppm}$, ${ }^{13} \mathrm{CO}_{2}=, \mathrm{H}_{2} \mathrm{O}=2 \%$ and $\mathrm{CH}_{4}=2 \mathrm{ppm}$ ). The simulation results, shown in Figure 3, illustrate that $\mathrm{CO}_{2}$ absorption coefficient is $2.5 \times 10^{-7} \mathrm{~cm}^{-1}$ with negligible interference. Thus absorption transition $\mathrm{R}(36)$ at $6251.761 \mathrm{~cm}^{-1}$ is selected for the following $\mathrm{CO}_{2}$ measurement.

\subsection{Optical Resonator Design}

The optical resonator is shown in Figure 4. Two identical cavity mirrors M1 and M2 (Layertec) have a diameter of $12.7 \mathrm{~mm}$, a radius of curvature of $1000 \mathrm{~mm}$ and a reflectivity of higher than 99.99\% (@1500 1700 nm). Lens1 and Lens2 are adjustable focus aspherical collimators (CFC-8X-C, Throlabs, Newton, NJ, USA). To suppress the high-order modes, 
the laser beam is spatially filtered using a single-mode fiber before illuminating on the photodetector, achieving a high-order modes suppression ratio of better than 100:1. It should be noted that, most of the optical and mechanical components of the optical cavity are fixed with structural adhesive to adapt to the extreme marine environment and improve the system stability.

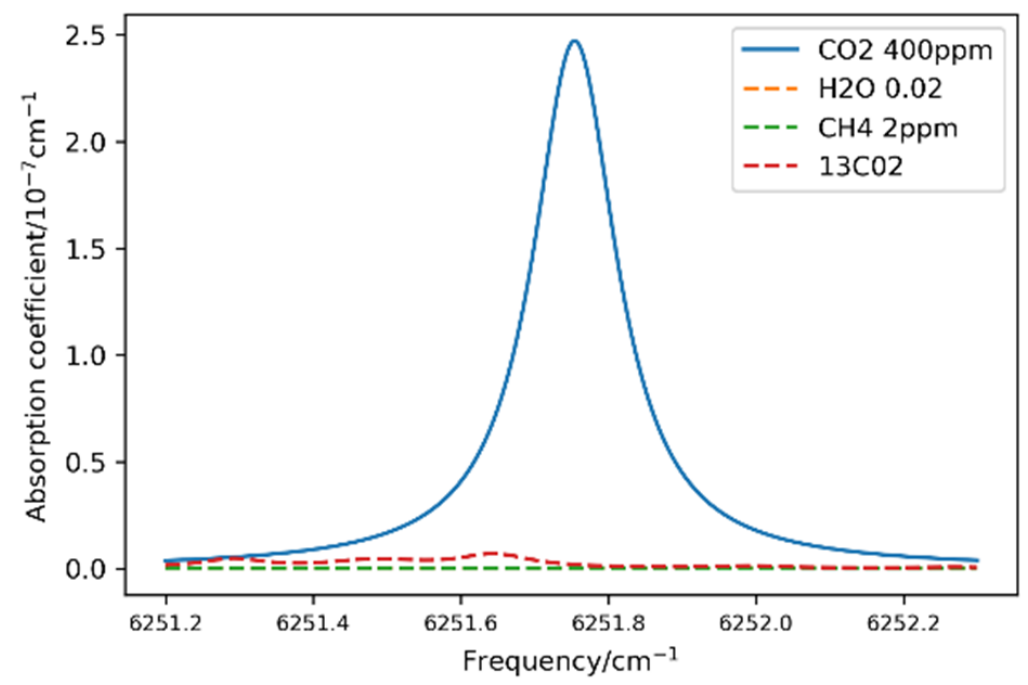

Figure 3. Simulation of $\mathrm{CO}_{2}$ absorption feature and background interference from of ${ }^{13} \mathrm{CO}_{2}, \mathrm{H}_{2} \mathrm{O}$ vapor and $\mathrm{CH}_{4}$.

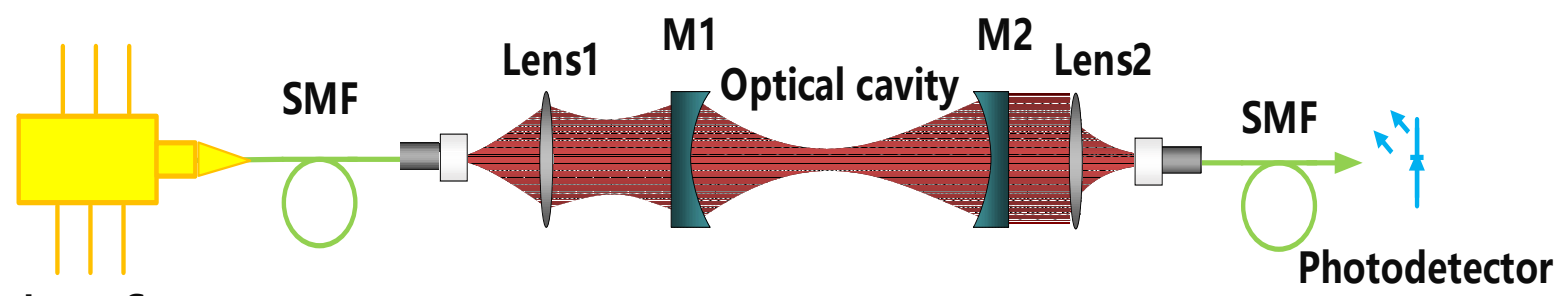

\section{Laser Source}

Figure 4. Framework of the optical resonant cavity, SMF: Single mode fiber; M1 and M2: cavity mirrors. Lens1 is a resonant cavity mode matching lens for mode matching of a laser-beam to a high finesse optical cavity. Lens2 is the light converging lens for coupling light into fiber.

\subsection{Longitudinal Mode Matching and Spectral Scanning}

The physical distance between the two cavity mirrors is $420 \mathrm{~mm}$, corresponding to a free spectral range (FSR) of $0.0119 \mathrm{~cm}^{-1}$. For each measurement using the continuous-wave CRDS system, the laser frequency is adjusted to resonate with one cavity mode. Since the cavity length remains stable during the measurement, the longitudinal cavity modes are used as the frequency reference to depict spectral absorption curve. To avoid potential spectral distortion from the longitudinal mode leakage during the spectral scanning process, we propose a strategy of longitudinal mode matching in a stepwise manner shown in Figure 5, and the step size is set as 1/5 FSR. Ideally, when the laser resonates with the longitudinal cavity mode q, 5 steps can rematch laser and the resonant cavity. However, it can be hardly realized due to the laser wavelength drift and cavity vibration. Differently, a high frequency sawtooth modulation (amplitude, $1 / 4 \mathrm{FSR} \leq \mathrm{M} \leq 2 / 5 \mathrm{FSR}$ ) is simultaneously superimposed on the step signal to ensure the resonance of each cavity mode with the laser. In the implementation of this strategy, each longitudinal mode resonates at least once in 5-step scanning, and at least one step does not resonate. The discrete spectrum can be obtained by taking the non-resonant step as a marker. 


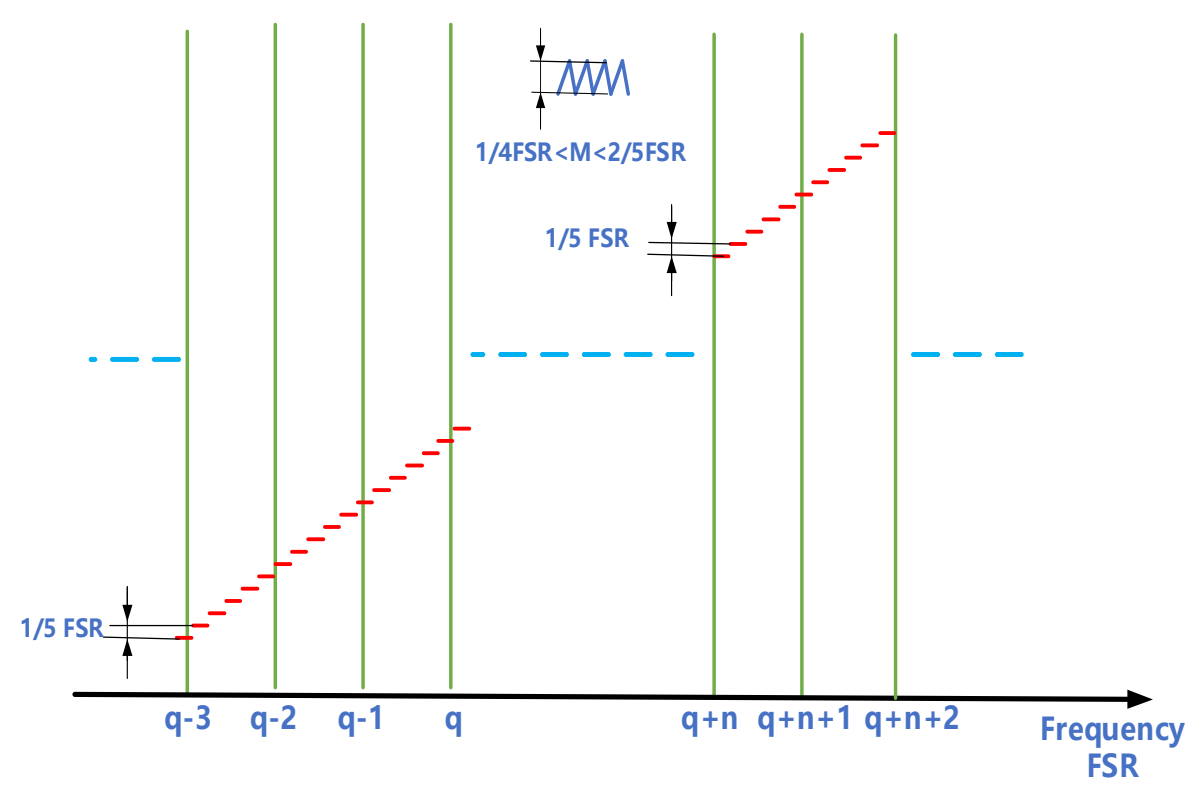

Figure 5. Schematic of the stepwise spectral scanning.

\section{Experimental Results}

\subsection{Sensor Performance}

After assembling the sensor, calibrated $\mathrm{CO}_{2}$ sample with a certain concentration of 885 ppm (uncertainty, 1\%) was sealed inside the gas chamber. The absorption spectrum of $\mathrm{CO}_{2}$ is obtained using the method described in Section 3.3. Voigt spectrum fitting was performed using a Python LMFIT-based program. Figure 6 presents a direct comparison between raw spectrum data of and the fitting curve, and a residual error of $1.5 \times 10^{-9} \mathrm{~cm}^{-1}$. The SNR is calculated to be 500 , corresponding to a detection limit of $1.8 \mathrm{ppm}$.

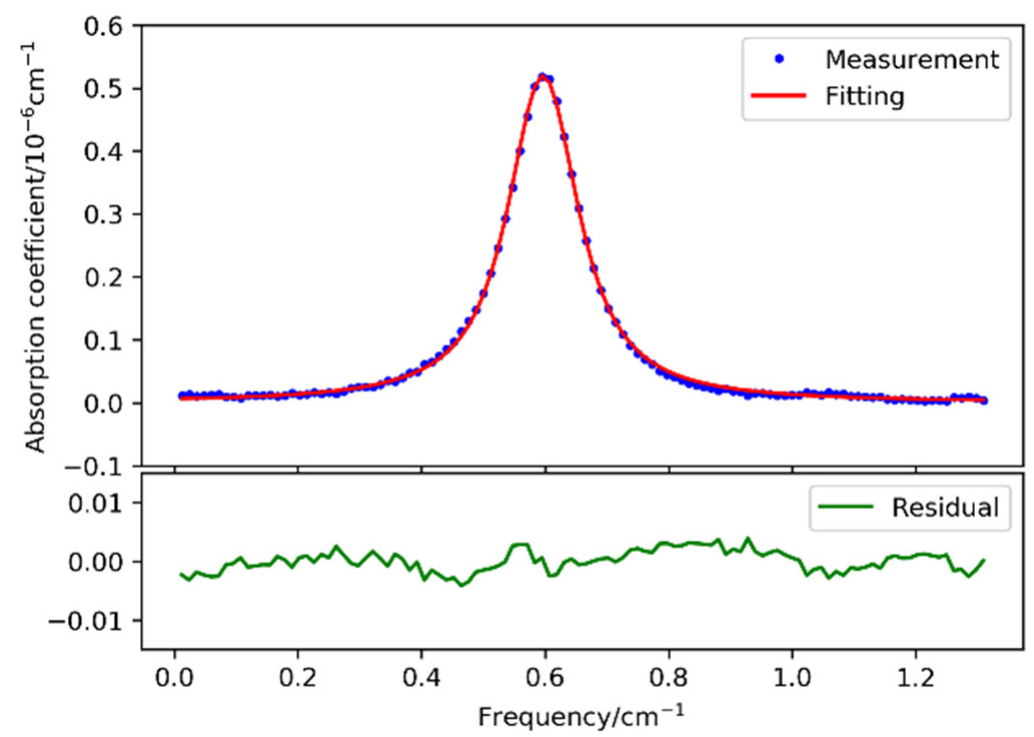

Figure 6. Comparison of the measured $\mathrm{CO}_{2}$ spectral data and Voigt fitting curve.

$\mathrm{CO}_{2}$ samples with different concentration of 2000 ppm, 1600 ppm, 1000 ppm, 500 ppm and $250 \mathrm{ppm}$ were generated by diluting the calibrated $10000 \mathrm{ppm} \mathrm{CO}_{2}$ with pure $\mathrm{N}_{2}$. The uncertainty for above samples is $1 \%$, mainly introduced by the dilution system. The mass flow meter was used to control the inlet flow rate at $50 \mathrm{~mL} / \mathrm{min}$. A continuous measurement of each $\mathrm{CO}_{2}$ sample was performed over $45 \mathrm{~min}$ and the experimental results are shown in Figure 7a. 


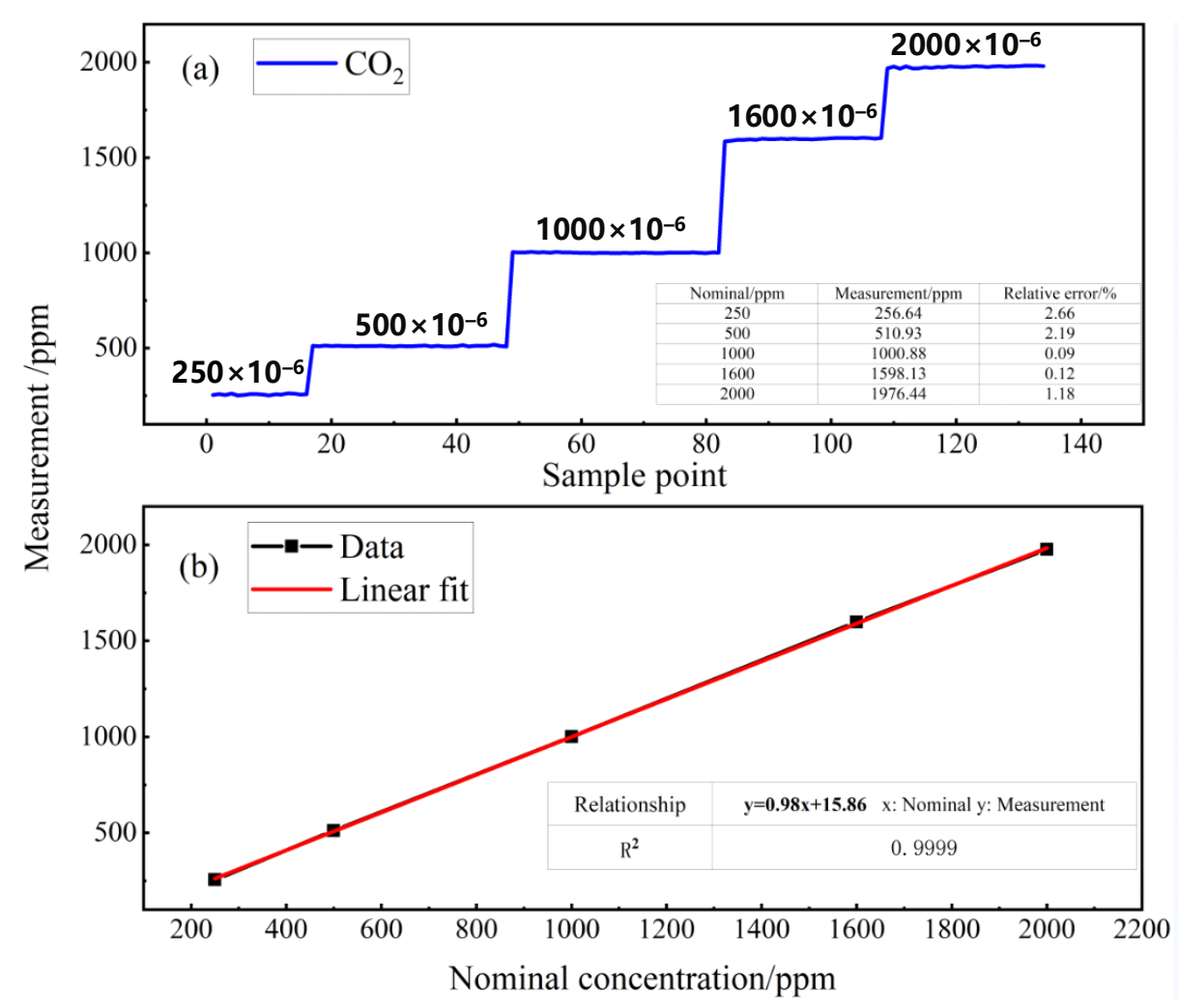

Figure 7. (a) Measured results of $\mathrm{CO}_{2}$ samples ranging from $250 \mathrm{ppm}$ to $2000 \mathrm{ppm}$ and (b) a linear fit to the measured data.

A linear fit, shown in Figure $7 b$, was thus performed to the measured data and the R-square value was calculated to be 0.9999 , illustrating a good linear response to the $\mathrm{CO}_{2}$ concentration from $250 \mathrm{ppm}$ to $2000 \mathrm{ppm}$. The relative error of the measured values of the five groups of standard gases is less than $2.66 \%$, which is consistent with the uncertainty of the standard gases.

To prove the feasibility, a long-term $(8 \mathrm{~h})$ comparison experiment was carried out between this sensor and one commercial land-based instrument CRDS instrument (G2201-i, Picarro). The gas pipelines of G2201-i and this sensor were connected together to guarantee the same the analyte was simultaneously and separately measured. The comparison result, shown in Figure 8, demonstrates that the measured $\mathrm{CO}_{2}$ concentration and its variation trend are consistent with each other and the maximum relative difference is within $1.3 \%$.

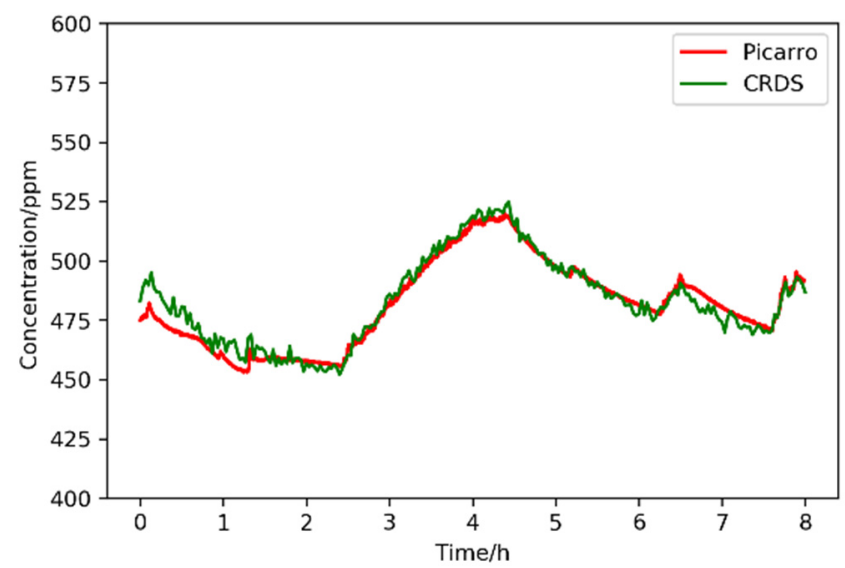

Figure 8. Comparison of this sensor to one commercial CRDS instrument (G2201-i, Picarro, Santa Clara, CA, USA). 


\subsection{Verification of Exponential Fit Retrieval Method for Dissolved $\mathrm{CO}_{2}$ Concentration}

Sample solutions are prepared by mixing $2000 \mathrm{ppm} \mathrm{CO}_{2}$ and pure $\mathrm{N}_{2}$ (purity: 99.99\%) using two mass flow meters (AST10-DLCMX-100C-025-A2B2-4VE, Asert, Franklin, MA, USA), as shown in Figure 9a. A submersible pump (SBE-5T, SEA-BIRD, Bellevue, WA, USA) is used to continuously cycle the solution through the PDMS module to separate dissolved $\mathrm{CO}_{2}$ to be measured. PDMS module is connected to the chamber of in-situ measurement system via a stainless tube. After 12-h measurement, the exponential model combined with Levenberg Marquardt (LM) algorithm is performed on the measured data. Figure $9 \mathrm{~b}$ depicts the results with a R-square of $99.84 \%$, when gas-phase $\mathrm{CO}_{2}$ concentration in the chamber is lower than the dissolved $\mathrm{CO}_{2}$. Figure $9 \mathrm{c}$ depicts the results with a $\mathrm{R}$-square of $98.71 \%$ when gas-phase $\mathrm{CO}_{2}$ concentration in the chamber is higher than the dissolved $\mathrm{CO}_{2}$. The coefficient $\frac{D_{G} S_{G} A}{l V}$, independent from the gas concentration, inside and outside the membrane are 0.1389 and 0.1444 , respectively. The coefficients of two different situations are consistent with each other with a small difference of $3.8 \%$. Thus, the method of exponential fit for dissolved gas concentration proves to be validated.

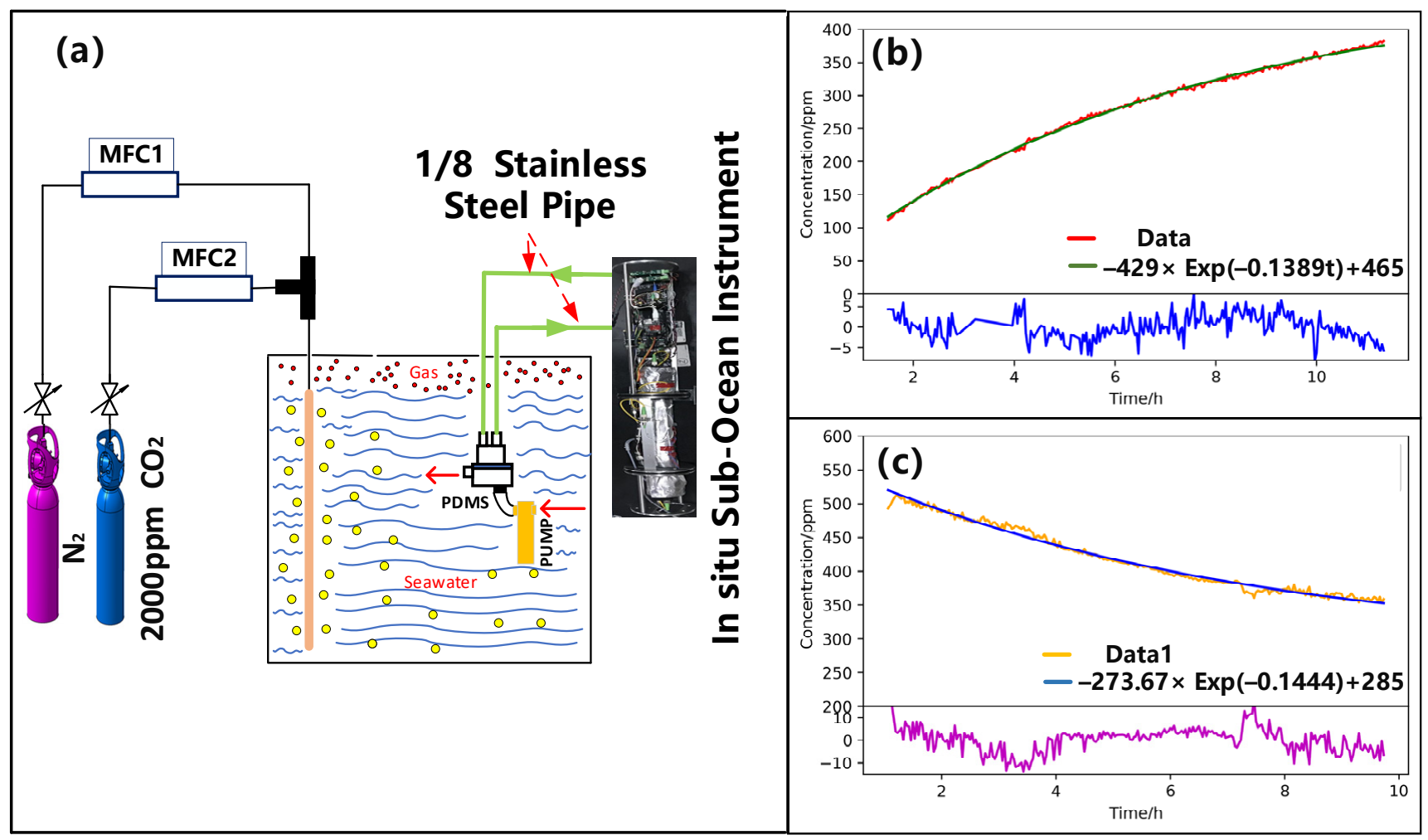

Figure 9. (a) Schematic of sample solution preparation and dissolved $\mathrm{CO}_{2}$ measurement system. Real-time concentration measurements when $\mathrm{CO}_{2}$ concentration in the cavity is (b) lower and (c) higher than the dissolved $\mathrm{CO}_{2}$, respectively.

\subsection{In-Situ Detection of Dissolved $\mathrm{CO}_{2}$ in Seawater}

From 6 to 7 March 2021, an in-situ observation was carried out near the coast of Sanya Institute of Deep Sea, Chinese Academy of Sciences, Sanya, Hainan Province. Figure 10 shows the observation location.

At the beginning of measurement, about $1100 \mathrm{ppm} \mathrm{CO}_{2}$ was filled in the cavity to quickly balance the concentration inside and outside the membrane. Figure 11 shows the observation result, the whole measurement is divided into two unstable parts and one stable part. In the first unstable part $(3 \mathrm{~h})$, the measured concentration was higher than that of seawater dissolved $\mathrm{CO}_{2}$ due to the presence of $1100 \mathrm{ppm} \mathrm{CO}_{2}$ in the measurement chamber, and the $\mathrm{CO}_{2}$ diffused from the measurement chamber into seawater. The concentration of seawater dissolved $\mathrm{CO}_{2}$ is calculated to be $850 \mathrm{ppm}$. In the second stable part $(9 \mathrm{~h})$, the 
gas concentration inside and outside the membrane remained equal, and the dissolved gas concentration fluctuated between $950 \mathrm{ppm}$ to $980 \mathrm{ppm}$. In the third unstable part $(8 \mathrm{~h})$, the concentration of dissolved $\mathrm{CO}_{2}$ decreased and the $\mathrm{CO}_{2}$ in the cavity continued to diffuse into seawater. The concentration of dissolved $\mathrm{CO}_{2}$ in the water is calculated to be $808 \mathrm{ppm}$. Interestingly, these measured dissolved $\mathrm{CO}_{2}$ concentrations are much higher than the atmospheric $\mathrm{CO}_{2}$ concentration, about $400 \mathrm{ppm}$, mainly because of a number of yachts cruising near the coast and the tide phenomenon.

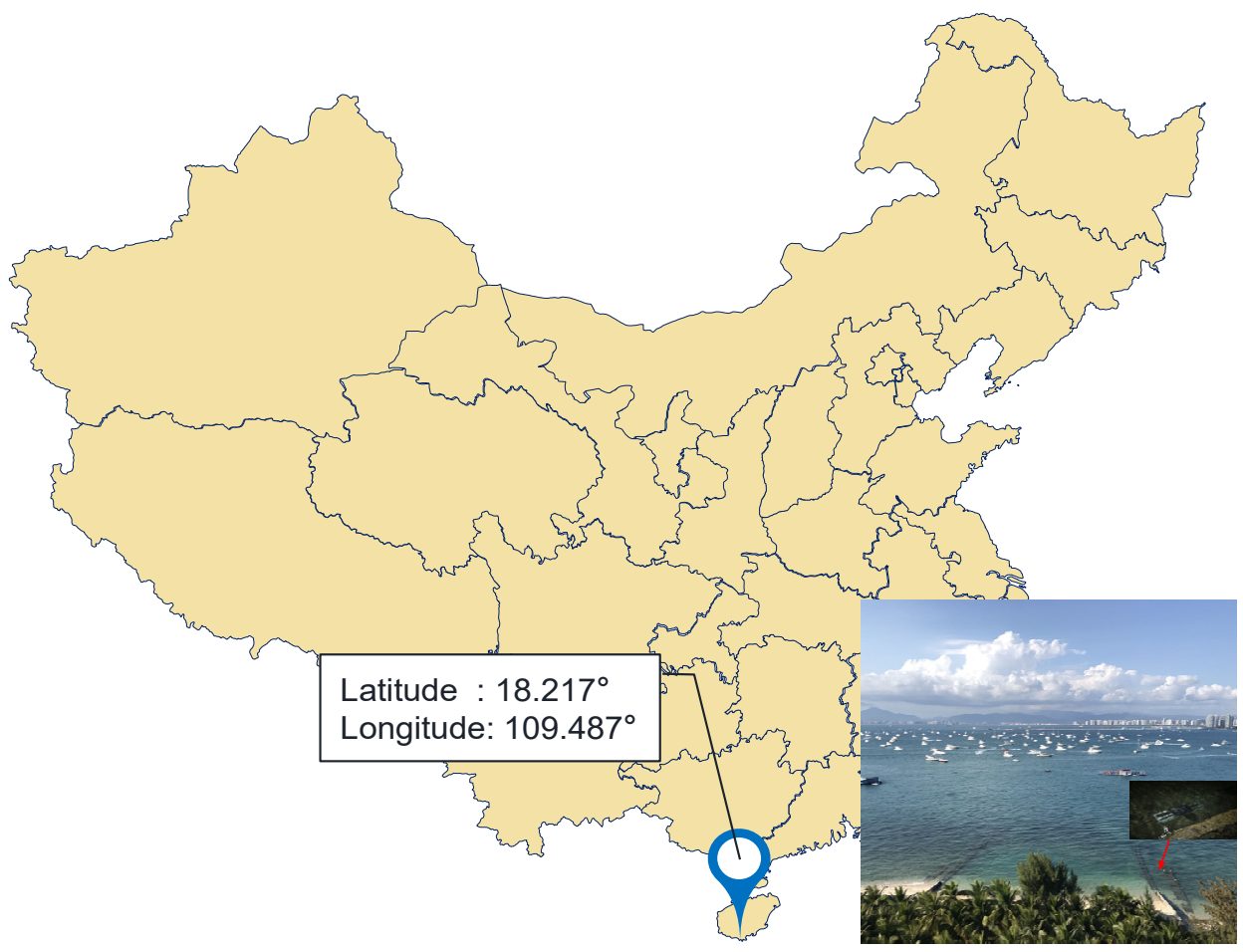

Figure 10. The in-situ test site is located at $18.217^{\circ}$ north latitude and $109.487^{\circ}$ east longitude.

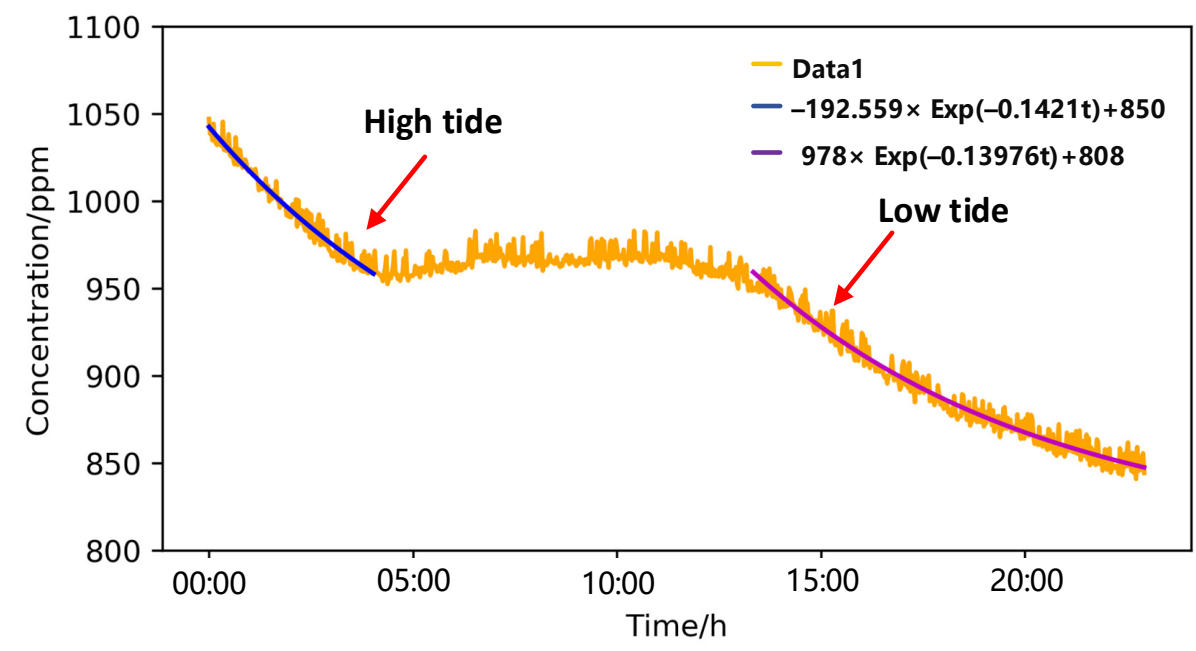

Figure 11. The result of In-situ measurements near coast.

\section{Conclusions}

We develop a fiber-integrated in-situ dissolved $\mathrm{CO}_{2}$ sensor using CRDS, in which a PDMS membrane is employed for water/gas separation and enrichment, and an exponential regression model is proposed for fast dissolve $\mathrm{CO}_{2}$ retrieval. The model feasibility is verified by performing a comparison test under two different situations, i.e., measurement 
chamber $\mathrm{CO}_{2}$ concentration is higher and lower than the dissolved $\mathrm{CO}_{2}$ concentration. Both their R-square of fitting are better than $98.5 \%$ and the difference of the two individually measured PDMS membrane coefficient $\frac{D_{G} S_{G} A}{l V}$ is only $3.8 \%$. The whole absorption spectrum of $\mathrm{CO}_{2}$ can be obtained within $90 \mathrm{~s}$ and a detection sensitivity of $1.8 \mathrm{ppm}$ has been achieved. A near coast in-situ measurement has been implemented over $24 \mathrm{~h}$ and provided regular fluctuation of dissolved $\mathrm{CO}_{2}$ concentrations, which is due to the tide phenomenon. Future efforts will be made to improve the corrosion resistance ability by using titanium alloy stainless steel as the pressured chamber material and to improve the gas separation efficiency by increasing the membrane surface area. Therefore, the developed senor could act as a promising tool to achieve high-precision detection of dissolved gas in seawater and then support the investigation on the ocean, such as vertical dissolved $\mathrm{CO}_{2}$ profile as deep as $4500 \mathrm{~m}$ and long-term dissolved $\mathrm{CO}_{2}$ monitoring under deep-sea extreme environment window, e.g., hydrothermal and cold spring.

Author Contributions: Conceptualization, M.H. and B.C.; methodology, M.H. and R.K.; software, M.H. and L.Y.; validation, M.H. and C.Y.; formal analysis, X.C.; investigation, X.C.; resources, C.Y.; writing—original draft preparation, M.H.; writing—review and editing, R.K. All authors have read and agreed to the published version of the manuscript.

Funding: This research was supported by the Scientific Instrument Developing Project of the Chinese Academy of Sciences (YJKYYQ20190037), the Second Comprehensive Scientific Investigation of the Qinghai-Tibet Plateau(2019QZKK020802), the National Key Research and Development Project (2019YFB2006003) and the National Natural Science Foundation of China (61805286).

Institutional Review Board Statement: Not applicable.

Informed Consent Statement: Not applicable.

Data Availability Statement: The data that support the plots within this paper are available from the corresponding author on request basis.

Conflicts of Interest: The authors declare no conflict of interest.

\section{References}

1. Tanhua, T.; Bates, N.R.; Körtzinger, A. The Marine Carbon Cycle and Ocean Carbon Inventories. In Ocean Circulation and Climate A 21st Century Perspective; Academic Press: Cambridge, MA, USA, 2013; pp. 787-815.

2. Dickens, G.R. Rethinking the global carbon cycle with a large, dynamic and microbially mediated gas hydrate capacitor. Earth Planet. Sci. Lett. 2003, 213, 169-183. [CrossRef]

3. Lechtenfeld, O.J.; Hertkorn, N.; Shen, Y.; Witt, M.; Benner, R. Marine sequestration of carbon in bacterial metabolites. Nat. Commun. 2015, 6, 6711. [CrossRef]

4. Wankel, S.D.; Germanovich, L.N.; Lilley, M.D.; Genc, G.; DiPerna, C.J.; Bradley, A.S.; Olson, E.J.; Girguis, P.R. Influence of subsurface biosphere on geochemical fluxes from diffuse hydrothermal fluids. Nat. Geosci. 2011, 4, 461-468. [CrossRef]

5. Nicholson, D.P.; Michel, A.P.M.; Wankel, S.D.; Manganini, K.; Sugrue, R.A.; Sandwith, Z.O.; Monk, S.A. Rapid Mapping of Dissolved Methane and Carbon Dioxide in Coastal Ecosystems Using the Chem Yak Autonomous Surface Vehicle. Environ. Sci. Technol. 2018, 52, 13314-13324. [CrossRef] [PubMed]

6. Lohrenz, S.E.; Cai, W.J.; Chakraborty, S.; Huang, W.J.; Guo, X.; He, R.; Xue, Z.; Fennel, K.; Howden, S.; Tian, H. Satellite estimation of coastal $\mathrm{pCO}_{2}$ and air-sea flux of carbon dioxide in the northern Gulf of Mexico. Remote. Sens. Environ. 2018, 207, 71-83. [CrossRef]

7. Michel, A.P.M.; Wankel, S.D.; Kapit, J.; Sandwith, Z.; Girguis, P.R. In situ carbon isotopic exploration of an active submarine volcano. Deep Sea Res. Part II Top. Stud. Oceanogr. 2018, 150, 57-66. [CrossRef]

8. Chua, E.J.; Savidge, W.; Short, R.T.; Cardenas-Valencia, A.M.; Fulweiler, R.W. A Review of the Emerging Field of Underwater Mass Spectrometry. Front. Mar. Sci. 2016, 3, 209. [CrossRef]

9. Wankel, S.D.; Joye, S.B.; Samarkin, V.A.; Shah, S.R.; Friederich, G.; Melas-Kyriazi, J.; Girguis, P.R. New constraints on methane fluxes and rates of anaerobic methane oxidation in a Gulf of Mexico brine pool via in situ mass spectrometry. Deep Sea Res. Part II Top. Stud. Oceanogr. 2010, 57, 2022-2029. [CrossRef]

10. Wang, Z.; Wang, Q.; Ching, J.Y.L.; Wu, J.C.-Y.; Zhang, G.; Ren, W. A portable low-power QEPAS-based CO 2 isotope sensor using a fiber-coupled interband cascade laser. Sens. Actuators B Chem. 2017, 246, 710-715. [CrossRef]

11. Wankel, S.D.; Huang, Y.W.; Gupta, M.; Provencal, R.; Leen, J.B.; Fahrland, A.; Vidoudez, C.; Girguis, P.R. Characterizing the distribution of methane sources and cycling in the deep sea via in situ stable isotope analysis. Environ. Sci. Technol. 2013, 47, 1478-1486. [CrossRef] 
12. Liu, Z.; Zheng, C.; Zhang, T.; Li, Y.; Ren, Q.; Chen, C.; Ye, W.; Zhang, Y.; Wang, Y.; Tittel, F.K. Midinfrared Sensor System Based on Tunable Laser Absorption Spectroscopy for Dissolved Carbon Dioxide Analysis in the South China Sea: System-Level Integration and Deployment. Anal. Chem. 2020, 92, 8178-8185. [CrossRef]

13. Graziani, S.; Beaubien, S.E.; Bigi, S.; Lombardi, S. Spatial and temporal $\mathrm{pCO}_{2}$ marine monitoring near Panarea Island (Italy) using multiple low-cost GasPro sensors. Environ. Sci. Technol. 2014, 48, 12126-12133. [CrossRef] [PubMed]

14. Zhang, H.; Jin, W.; Hu, M.; Hu, M.; Liang, J.; Wang, Q. Investigation and Optimization of a Line-Locked Quartz Enhanced Spectrophone for Rapid Carbon Dioxide Measurement. Sensors 2021, 21, 5225. [CrossRef] [PubMed]

15. Xia, J.; Feng, C.; Zhu, F.; Ye, S.; Zhang, S.; Kolomenskii, A.; Wang, Q.; Dong, J.; Wang, Z.; Jin, W.; et al. A sensitive methane sensor of a ppt detection level using a mid-infrared interband cascade laser and a long-path multipass cell. Sens. Actuators B Chem. 2021, 334, 129641. [CrossRef]

16. Boulart, C.; Connelly, D.P.; Mowlem, M.C. Sensors and technologies for in situ dissolved methane measurements and their evaluation using Technology Readiness Levels. TrAC Trends Anal. Chem. 2010, 29, 186-195. [CrossRef]

17. Maity, A.; Maithani, S.; Pradhan, M. Cavity Ring-Down Spectroscopy: Recent Technological Advancements, Techniques, and Applications. Anal. Chem. 2021, 93, 388-416. [CrossRef] [PubMed]

18. Zhao, G.; Hausmaninger, T.; Ma, W.; Axner, O. Differential noise-immune cavity-enhanced optical heterodyne molecular spectroscopy for improvement of the detection sensitivity by reduction of drifts from background signals. Opt. Express 2017, 25, 29454-29471. [CrossRef]

19. Wu, H.; Stolarczyk, N.; Liu, Q.H.; Cheng, C.F.; Hua, T.P.; Sun, Y.R.; Hu, S.M. Comb-locked cavity ring-down spectroscopy with variable temperature. Opt. Express 2019, 27, 37559-37567. [CrossRef]

20. Hua, T.P.; Sun, Y.R.; Wang, J.; Liu, A.W.; Hu, S.M. Frequency metrology of molecules in the near-infrared by NICE-OHMS. Opt. Express 2019, 27, 6106-6115. [CrossRef]

21. Chen, Y.; Lehmann, K.K.; Kessler, J.; Sherwood Lollar, B.; Couloume, G.L.; Onstott, T.C. Measurement of the ${ }^{13} \mathrm{C} /{ }^{12} \mathrm{C}$ of atmospheric CH4 using near-infrared (NIR) cavity ring-down spectroscopy. Anal. Chem. 2013, 85, 11250-11257. [CrossRef]

22. Gupta, P.; Noone, D.; Galewsky, J.; Sweeney, C.; Vaughn, B.H. Demonstration of high-precision continuous measurements of water vapor isotopologues in laboratory and remote field deployments using wavelength-scanned cavity ring-down spectroscopy (WS-CRDS) technology. Rapid Commun. Mass Spectrom. 2009, 23, 2534-2542. [CrossRef] [PubMed]

23. Wang, Z.; Wang, Q.; Zhang, W.; Wei, H.; Li, Y.; Ren, W. Ultrasensitive photoacoustic detection in a high-finesse cavity with Pound-Drever-Hall locking. Opt. Lett. 2019, 44, 1924-1927. [CrossRef] [PubMed]

24. Ismail, A.F.; Kusworoa, D.T.; Mustafa, A.; Hasbullaha, H. Understanding the Solution-Diffusion Mechanism in Gas Separation Membrane for Engineering Students [C]. In Proceedings of the 2005 Regional Conference on Engineering Education, Fayetteville, AR, USA, 14-26 September 2005.

25. Lin, D.; Ding, Z.; Liu, L.; Ma, R. A Method to Obtain Gas-PDMS Membrane Interaction Parameters for UNIQUAC Model. Chin. J. Chem. Eng. 2013, 21, 485-493. [CrossRef]

26. Sysoev, A.A. A Mathematical Model for Kinetic Study of Analyte Permeation from Both Liquid and Gas Phases through Hollow Fiber Membranes into Vacuum. Anal. Chem. 2000, 72, 4221-4229. [CrossRef]

27. Bell, R.J.; Short, R.T.; Vanamerom, F.H.W.; Byrne, R.B. Calibration of an In Situ Membrane Inlet Mass Spectrometer for Measurements of Dissolved Gases and Volatile Organics in Seawater. Environ. Sci. Technol. 2007, 41, 8123-8128. [CrossRef]

28. Lehmann, K.K.; Berden, G.; Engeln, R. An Introduction to Cavity Ring-Down Spectroscopy. In Cavity Ring-Down Spectroscopy; John Wiley \& Sons: Hoboken, NJ, USA, 2009; pp. 1-26.

29. Chen, J.-Y.; Liu, J.-G.; He, Y.-B.; Wang, L.; Gang, Q.; Xu, Z.-Y.; Yao, L.; Yuan, S.; Ruan, J.; He, J.-F.; et al. Study of CO 2 spectroscopic parameters at high temperature near $2.0 \mu \mathrm{m}$. Acta Phys. Sin. 2013, 62, 224206.

30. Gordon, I.E.; Rothman, L.S.; Hill, C.; Kochanov, R.V.; Tan, Y.; Bernath, P.F.; Birk, M.; Boudon, V.; Campargue, A.; Chance, K.V.; et al. The HITRAN2016 molecular spectroscopic database. J. Quant. Spectrosc. RA 2017, 203, 3-69. [CrossRef] 